\title{
Neoliberalismo y derechos humanos
}

\author{
Álvaro ECheheVerri UruburU*
}

Fecha de recibido: 6 de febrero de 2006

Fecha de aprobación: 14 de marzo de 2006

\section{RESUMEN}

El artículo analiza como la implementación del modelo económico de libre mercado ha provocado una ruptura con la propuesta de justicia social y de los derechos económicos, sociales y culturales que están presentes en la Constitución de Colombia de 1991. La ruptura del Estado social ocasiona un mayor desequilibrio en la sociedad y trae como consecuencia el desmejoramiento de los derechos sociales conquistados por los trabajadores a lo largo del siglo XX.

\section{PALABRAS CLAVE}

Globalización, neoliberalismo, derecho laboral.

\section{ABSTRACT}

The article analyzes how the implementing of the free market economic model had provoked the rupture with the social justice proposal and with the economic, social and cultural rights that are present in the 1991 Colombian Constitution. The rupture of the social state causes a grater unbalance in the society and brings as a consequence, the deterioration of the social rights gotten by workers along the XX century.

\section{KEY WORDS}

Globalization, neoliberalism, labor law.

Decano de la Facultad de Derecho de la Universidad Santo Tomás, Ex-constituyente, Ex -magistrado del Consejo Superior de la Judicatura. Conferencia dictada en el marco del II Congreso Internacional de "Economía, Ética y Alternativas de Desarrollo", organizado por la Facultad de economía de la Universidad Santo Tomás de Bogotá, 2005. 


\section{Introducción}

Si la economía es la ciencia que estudia la producción y distribución de bienes que por naturaleza son escasos, surgen a partir de dicho concepto varios interrogantes: ¿de qué producción y distribución se trata?, ¿de todos los objetos posibles calificables como bienes?, o ¿tan sólo de aquellos que son esenciales a la existencia y perfeccionamiento del ser humano? Si se trata o importa la distribución de estos últimos, ipuede la ciencia económica garantizar una distribución justa y equitativa, esto es, que tales bienes esenciales lleguen a la mayor parte de la población de un país?

Como se observa, tales preguntas desembocan en una encrucijada de tipo ético, que algunas escuelas económicas quieren hoy eludir o situar exclusivamente en el aspecto de la producción, bajo una ilusoria suposición según la cual el aumento incesante de ésta y la colocación de sus productos en los mercados internacionales automáticamente conducirá al mejoramiento en las condiciones de vida de todos los miembros de la sociedad. Es decir, que todos ellos, de acuerdo a una "armonía preestablecida" -que se quiere validar empíricamente con algunos ejemplos exitosos de desarrollo económico-social- alcanzarían a acceder a los bienes esenciales para su subsistencia, incluso a muchos más, medidos en términos de adquisición de bienes culturales costosos o a mayores horas de descanso y ocio dedicadas a actividades creativas.

El acceso a aquellos bienes que se consideran esenciales para una vida digna comporta la realización plena de los derechos humanos, pues el contenido de éstos ha dejado de comprender exclusivamente los derechos individuales (derecho a la vida y a la integridad personal, derecho a la libertad de conciencia y de expresión, derechos políticos, derechos procesales, etc.) de las constituciones liberales de los siglos XVIII y XIX, para incorporar los llamados derechos económicos, sociales y culturales, presentes en todas las cartas políticas de Occidente desde las constituciones mexicana de 1917, Rusa de 1918 y Alemana de Weimar de 1919. El plexo de tales derechos comprende, entre otros derechos: el de tener un trabajo digno y justamente remunerado; el de acudir a medios de presión legítimos, como la huelga, para obtener una mejor remuneración y dignas condiciones laborales; el de la negociación colectiva para contrabalancear, con el poder de la unión de la clase, la superioridad fáctica de los dueños del capital; el de poseer una vivienda digna; el tener cubiertas las eventualidades en salud y la garantía de una subsistencia con dignidad una vez se deje de ser útil laboralmente por enfermedad o vejez, y el de acceso a la educación como mecanismo para la creación de condiciones de igualdad de oportunidades para todos los miembros de la sociedad. No sobra aclarar que tales derechos, no obstante su tardía proclamación y consagración en los ordenamientos jurídicos de los Estados capitalistas, no poseen una jerarquía menor a los tradicionales derechos civiles y políticos de más antigua introducción en los textos jurídicos, pues todos los derechos conforman una unidad inescindible en correspondencia con la unidad biosíquica que constituye al ser humano. Pero, además, el goce y realización de los derechos económicos y sociales, establecen las condiciones de posibilidad existencial de los derechos estrictamente subjetivos.

El credo filosófico-económico del neoliberalismo, asociado a los procesos de globalización en curso, al cuestionar el papel del Estado en la dirección de la economía en procura de la realización de la justicia social, esto es, de la efectivización precisamente de los derechos económicos, sociales y culturales, ha empobrecido a tal punto el nivel de las reivindicaciones de los sectores más deprimidos de la sociedad que el amplio espectro de esos derechos se ha visto reducido a un 
único derecho, proclamado amargamente por Amarthya Sen, el "derecho a no tener hambre".

Analizaremos por tanto a continuación: a) la ruptura del pacto social del Estado capitalista contemporáneo como consecuencia de las políticas económicas del neoliberalismo, b) la concepción ética sobre la cual se sustentan dichas políticas, y e) las implicaciones para los derechos humanos derivados de la aplicación de esas mismas políticas.

\section{La ruptura del pacto social}

La carrera triunfal del neoliberalismo en prácticamente todas las democracias capitalistas a partir de la década de los setenta del siglo pasado ha significado el desmonte del llamado "Estado benefactor" o "Estado social de derecho", manifestado de manera visible en las políticas públicas de supresión de toda la normatividad intervencionista encaminada a regular la utilización de la fuerza laboral, en los viejos términos de "negociación entre capital y trabajo", que implicaba altas cargas para los empresarios en términos prestacionales y de estabilidad en el empleo.

El desmonte del "Estado social" comportó, de manera más radical todavía, la abolición de uno de los rasgos más sobresalientes de dicho tipo de Estado, la política social, mediante la reducción considerable, si no su supresión absoluta, de los gastos sociales del Estado (subsidios al desempleo, universalidad de la seguridad social, construcción de vivienda para los sectores más pobres, educación pública o medidas de subsidio a ésta, etc.).

Como lo señalara Pedro Medellín: "Ios recortes a los programas de becas y asistencia para los estudiantes de las escuelas públicas; a los programas de asistencia para los ancianos y desem- pleados; y la cada vez mayor privatización de los servicios públicos se constituyen en el denominador común de la gestión gubernamental... desde los primeros años de la década de los ochenta"1.

El desmonte de las políticas redistributivas que caracterizaron al "Estado Social", ha implicado la ruptura del pacto social sobre el cual se asentó, desde la década de los cincuenta del siglo pasado, la legitimidad de los Estados capitalistas desarrollados y que, en términos generales, condujo al mejoramiento sustancial en los niveles de vida de su población.

El pacto social, en términos elementales, significó el que a cambio de abandonar la pretensión de abolir de manera radical el orden capitalista, los sectores hasta entonces marginados y excluidos de las ventajas del progreso, que dicho orden deparaba solamente a unos pocos, entraran a participar en dichas ventajas gracias a la acción decidida del Estado para establecer verdaderas condiciones de "igualdad de oportunidades" que anulasen las inequidades y desequilibrios que las fuerzas del mercado, por sí solas y sin control, necesariamente generan.

La sanción de dicho pacto, que legitimó y estabilizó durante varios años a las democracias capitalistas, se expresó mediante la introducción en las constituciones de la segunda mitad del siglo XX del concepto de "Estado social y democrático de derecho", como fórmula jurídica rectora y orientadora de las políticas públicas de naturaleza redistributiva.

En los Estados en proceso de desarrollo, las políticas neoliberales impuestas por los organismos multilaterales de crédito (Banco Mundial, Fondo Monetario Internacional), orientadas a facilitar la

MEDELLíN, Pedro. La reforma del Estado en América Latina: desnacionalización del Estado y transnacionalización del capital. Bogotá: FESCOL, 1989, p. 83. 
inserción de sus economías en la economía mundial (vg; control de gasto público con la consiguiente reducción de su componente social; la desregularización en la utilización de la fuerza laboral; privatización y encarecimiento de la seguridad social, etc.), han impedido la instauración del modelo del "Estado social", contrariamente a las proclamaciones constitucionales, tal como ha venido sucediendo en el caso colombiano.

En definitiva, la legitimidad de las democracias en los países capitalistas desarrollados se ha tornado precaria, en la medida en que las políticas públicas de corte neoliberal pugnan y contradicen la fórmula política del "Estado social" consagrado constitucionalmente y a la cual dichas democracias no se atreven a renunciar, produciéndose la situación paradójica que denuncia el jurista español Miguel Ángel García Herrera, cuando sostiene: "así, la modificación del contexto ideológico-político ocurrido durante los últimos decenios, que tiende a sustituir los principios de solidaridad social por las exigencias de un orden competitivo, conservando un mínimo de prestaciones sociales para mantener la legitimidad del sistema, "amenaza con transformar a la Constitución en un islote socialdemócrata inmerso en un océano neoliberal..."2.

En los países subdesarrollados, particularmente en América Latina, en razón de una legitimidad no alcanzada como consecuencia del abandono de las débiles políticas sociales del pasado, el concepto mismo de la "democracia" se ha devaluado para la mayoría de la población, al punto que ésta se inclina por la instauración de gobiernos autoritarios que prometan un cambio en las condiciones de pobreza y miseria generalizada que agobian a la región, tal como lo demostró el informe del PNUD sobre la democracia en América Latina (2003).

\section{La ética del neoliberalismo}

El discurso del neoliberalismo es, antes que una teoría económica, un discurso ideológico con fuertes connotaciones éticas.

En efecto, para sus epígonos la desigualdad de los seres humanos es una virtud, necesaria para el desarrollo económico y la eficiencia del sistema: "Los nuevos ricos, dice Von Mises, son los precursores del progreso económico". La desigualdad en la riqueza y el ingreso es defendida entonces como uno de los rasgos de la economía de mercado; su función es suministrar incentivos al individuo para que obtenga lo mejor de sus habilidades y oportunidades. Para dicho pensador Austríaco, la lucha por la igualdad de oportunidades en la que se ha empeñado el Estado social menoscaba el principio de desigualdad como motor de la acumulación de capital ${ }^{3}$.

Si la desigualdad puede ser justificada y más aún exaltada como necesaria, nada tiene que hacer la justicia social como propósito del Estado; ello por cuanto la distribución de bienes y riquezas que efectúa el mercado será siempre justa porque obedecerá, en todo caso, a la lógica de éste, a su racionalidad interna y natural. Por eso Hayek, otro ideólogo del neoliberalismo, sostiene que si se permite al mecanismo de libre mercado actuar por sí mismo, sin las interferencias distorsionantes del Estado, éste recompensará a los individuos de acuerdo con su contribución productiva a la sociedad "generándose así una distribución naturalmente justa"4.

GARCÍA HERRERA, Miguel Ángel "Poder judicial y Estado social: legalidad y resistencia constitucional”. En: PERFECTO IBÁÑEZ, Andrés (ed.). Corrupción y Estado de derecho. Madrid: Trotta, 1996. p. 69.

3 AHUMADA, Consuelo. El modelo neo-liberal y su impacto en la sociedad colombiana. Bogotá: Áncora 1997, p. 115.

$4 \quad$ Ibíd., p. 177. 
La consecuencia lógica de las posiciones neoliberales en favor de la desigualdad y de extrañamiento de cualquier tipo de justicia social es el de la defensa de la concentración de los bienes y riquezas en pocas manos. Entre las medidas prácticas para lograrlo, recomiendan la abolición de los impuestos para las grandes compañías, así como la supresión de las tasas progresivas de tributación de acuerdo a los ingresos individuales. Milton Friedman, el más conocido de Ios pensadores neoliberales de la actualidad, sostiene que las exenciones tributarias para los más ricos -léase política tributaria del actual gobierno colombiano- "refuerza los mercados de capital, estimula el desarrollo de las empresas y promueve una efectiva competencia. La única responsabilidad social de las empresas es la de producir tanto dinero para los accionistas como les sea posible" ${ }^{\prime \prime}$.

La ética descarnada del neoliberalismo se enfrenta entonces a la ética humanista que informa al "Estado social":

Por oposición al principio de solidaridad que éste proclama, enfrenta el del individualismo; al de igualdad sustancial o material opone la racionalidad del mercado; a la planificación de la economía orientada a la obtención de la justicia social, enfrenta la libre competencia que a cada uno da lo que le corresponde en la lucha por la vida.

Bajo estos presupuestos ideológicos, y volviendo atrás en nuestra exposición, "el pacto social democrático -configurado en las democracias avanzadas e intentado en las débiles democracias de la periferia- ya no resulta vinculante (y obligatorio), debiéndose restaurar los instrumentos clásicos de la reproducción del sistema eco- nómico (capitalista): mercado, reducción del poder político en la economía, individualismo, quiebra de la presencia sindical" ${ }^{\prime \prime}$, que fue en el inmediato pasado factor de reequilibrio democrático de la sociedad.

\section{Consecuencias de las políticas neoliberales para la vigencia de los derechos humanos}

La integralidad de los derechos humanos, que incorpora los llamados "derechos económicos, sociales y culturales", se ha visto quebrantada gravemente en América Latina y particularmente en Colombia como consecuencia de las políticas neoliberales. Algunas cifras ilustran esta situación:

Desde que en el continente se impusieron dichas políticas, el número de pobres ha aumentado en más de 200 millones. En Colombia en los últimos 5 años este número se ha incrementado en 4 millones. El número de indigentes -es decir de pobres absolutos- ronda los 9 millones.

Para no hablar más que de un derecho fundamental, el derecho al trabajo, desde que el ideario neoliberal preside las políticas de los gobiernos en todo el mundo el problema del "empleo ha tenido un papel insignificante en la agenda del desarrollo internacional. Esto ha tenido, sin duda, su fuente en la globalización -sostiene la ex ministra Cecilia López Montaño ${ }^{7}$-, cuya prioridad sigue siendo el capital y no el ser humano. Se ha perdido el interés por la gente y se ha olvidado que, para la mayoría de los hombres y mujeres que laboran en el mundo, el acceso a un buen trabajo representa la diferencia entre una vida de pobreza y una esperanza y oportunidad económica".

Echeverri Uruburu, Álvaro. Teoría constitucional y ciencias políticas. Bogotá: Librería el Profesional, 2002, p. 149.

GARCÍA HERRERA, Miguel, Op. Cit., p. 68.

LÓPEZ MONTAÑO, Cecilia, “Trabajo digno: camino al desarrollo". Bogotá: Diario EL TIEMPO, septiembre de 2005. 
Las cifras de desempleo y subempleo en Colombia son francamente aterradoras y muy por encima de los demás países de la región, con excepción de Haití.

Si las cifras de desempleo siguen rondando, según el DANE, el 14\%, las del subempleo, con 7 millones de colombianos en edad de ocupar un empleo digno, con medio millón más de subempleados con respecto al último año, son alarmantes, en contra de la prédica optimista de ciertos sectores acerca de la recuperación de la economía del país.

Contrasta con esta visión optimista el hecho de que de cada 10 empleos creados 6 son informales. En cuanto al empleo formal, la mayoría es temporal. Todo ello implica "inestabilidad, poco consumo y por tanto reducido impacto en la demanda interna y en el crecimiento de la economía nacional" ${ }^{\prime 8}$.

Por eso, como dice el investigador peruano Adolfo Figueroa: "el mercado laboral opera como un mecanismo básico de exclusión social. De esta manera, peor aún que ser explotado es no serlo; es decir, que los que no son explotados (los no asalariados) son el grupo más pobre y excluido de la sociedad" ${ }^{\prime \prime}$.

En la fase actual del proceso globalizador, por tanto, la situación de los perdedores de este proceso -la mayoría de los habitantes del mundoparece mucho más dramática que en las etapas anteriores del desarrollo del capitalismo, pues como lo señala el gran sociólogo del derecho, Boaventura De Sousa Santos: "La situación descrita por Marx es bastante diferente de la que estamos viviendo hoy. Las clases dominadas de nuestro mundo parecen encajar en dos categorías, ninguna de ellas reducible a la clase que tiene sólo sus cadenas por perder. De un lado, sectores considerables de las clases trabajadoras tienen más que perder que sus cadenas, aún cuando ese "más" no sea mucho, o sea más simbólico que material. De otro lado, grandes poblaciones alrededor del mundo ni siquiera tienen cadenas, es decir, no son ni siquiera lo suficientemente fuertes o "útiles" para ser explotables en forma directa por el capital y, como consecuencia, la eventual ocurrencia de tal explotación sonaría para ellas como una liberación"10.

Si quisiéramos expresar en pocas palabras el efecto global de las políticas neoliberales, tendríamos que éstas han hecho más ricos a los ricos y más pobres a los pobres; igualmente, gracias a dichas políticas las naciones ricas son hoy mucho más ricas y las pobres se han hecho mucho más pobres.

Como lo recordaba el "Financial Times" de Londres: "Al iniciarse el siglo XIX el porcentaje de ingresos reales "per cápita" entre los países más ricos del mundo y los más pobres era de 3 a 1 . En 1900 era de 10 a 1 . Al iniciarse el año 2000 se elevó de 60 a 1"11.

\section{Conclusión}

En contra de la supuesta "modernidad" que dice representar el neoliberalismo, para quienes defendemos el valor eminente de la dignidad humana y la vigencia de los derechos fundamentales correspondientes a esa dignidad, la actual coyuntura nos obliga, desde la perspectiva del

\footnotetext{
$8 \quad$ Ibíd.

9 FIGUEROA, Adolfo. "Distribución de ingresos y pobreza en el Perú". Citado en documento del Módulo Privado, Facultad de Derecho, Universidad Santo Tomás, Bogotá: USTA, 2005, p. 9.

10 DE SOUZA SANTOS, Boaventura. La globalización del Derecho. Bogotá: Universidad Nacional de Colombia, 1998, p. 59.

11 ECHEVERRI URUBURU, Álvaro. Op. cit., p. 151.
} 
constitucionalismo social, coincidente con la del humanismo tomista, a situarnos en una posición de "resistencia constitucional" como la que defiende el jurista español Miguel García Herrera ${ }^{12}$.

Situarse en "resistencia constitucional" significa asumir, con todas sus implicaciones, el modelo constitucional que el país adoptó en 1991, fundado en el "Estado social y democrático de derecho" y que ha buscado superar el esquema de igualdad formal por el de la igualdad sustancial. Así, la constitución como ley positiva resulta ser el trasunto de la ley natural ordenada por el creador para el logro del bien común y la conservación del género humano.

Desde esta doble perspectiva, la del humanismo constitucional y la del humanismo tomista, economía y ética necesariamente deben converger, pues como señala John Rawls, no puede existir una "sociedad bien ordenada" si sus instituciones -incluidas las económicas- no se orientan hacia la realización de la justicia social a favor de quienes no resultaron favorecidos por la "Iotería de la vida".

\section{BIBLIOGRAFÍA}

AHUMADA, Consuelo. El modelo neoliberal y su impacto en la sociedad colombiana. Bogotá: ÁNCORA, 1997.

DE SOUZA SANTOS, Boaventura. La globalización del derecho. Bogotá: Universidad Nacional de Colombia, 1998.

ECHEVERRI URUBURU, Álvaro. Teoría constitucional y ciencia política. Bogotá: Librería el Profesional, 2002.

FIGUEROA, Adolfo. "Distribución de ingresos y pobreza en el Perú". Citado en: Módulo Privado, Universidad Santo Tomás, 2005.

GARCÍA HERRERA, Miguel Ángel. "Poder judicial y Estado social de derecho: legalidad y resistencia constitucional". En: PERFECTO IBÁÑEZ, Andrés (Ed.). Corrupción y Estado de derecho. Madrid: Trotta, 1996.

MEDELLíN, Pedro. La reforma del Estado en América Latina: desnacionalización del Estado y trasnacionalización del capital. Bogotá: FESCOL, 1989.

LÓPEZ MONTAÑO, Cecilia. “Trabajo digno, camino al desarrollo". Bogotá: Diario El Tiempo, septiembre 2005.

\footnotetext{
GARCíA HERRERA, Miguel A. Op. cit., p. 82.
} 